\title{
Factors Affecting Successful Implementation of Poverty Alleviation Policy in Sri Lanka
}

\author{
P. I Anuradha \\ Lecturer, University of Sri Jayewardenepura, Sri Lanka \\ E-mail: anuradhapathirage@ @jp.ac.lk \\ R. Lalitha S. Fernando \\ Senior Professor, University of Sri Jayewardenepura, Sri Lanka \\ E-mail: rlsf@sjp.ac.lk
}

Received: Aug. 23, 2017 Accepted: Dec. 17, 2017 Online published: Dec. 19, 2017

doi:10.5296/jpag.v7i4.12339 URL: https://doi.org/10.5296/jpag.v7i4.12339

\begin{abstract}
Poverty is a critical and social issue in the developing world. Various policy measures have been taken by the countries for reducing this issue. Similarly, Sri Lanka has been taken many initiatives. But the incidence of poverty has not come down as expected. For an example, the Poverty Head Count Ratio in rural sector was $29.4 \%$ in 1990 and $24.7 \%$ in 2012 (Census and Statistic Department in Sri Lanka). Among the many reasons for failure of these, poor implementation is imperative. In this context, this paper carries out an empirical study to identify the factors affecting successful implementation of poverty alleviation policy. Quantitative research method was used and primary data was gathered from 71 officers attached with the implementation process at the national, district, and divisional levels. A structured questionnaire was used with interviews for the data collection. Reliability analysis and factor analysis were undertaken to ensure the validity and reliability of the data. Correlation and regression analysis was undertaken in identifying the factors. The test result found that capability, disposition, number of people involved in the implementation, past experience of the implementing officers are significantly affecting on successful implementation of the policy. Based on the findings, policy measures are suggested for improving the policy implementation.
\end{abstract}

Keywords: poverty, poverty alleviation programs, policy implementation, success factors 


\section{Introduction}

Sri Lanka is an island of 65,610 square kilometers with a population of little over 20.4 million people. The country is divided into nine provinces and twenty five administrative districts. For the purpose of socio economic studies the country has also been divided into three sectors; the Urban, Rural and Estate. According to the figures of Central Bank Annual Report (2013), large regional disparities are seen (urban 18.35\%, rural 24.4\%, estates $12.62 \%$ ) in Sri Lanka. According to the indicators such as quantity of calorie intake, literacy, life expectancy, rate of infant deaths, equal status for women, environmental protection in development activities etc. Sri Lanka is in a high ranking position. Further, according to the Human Development Index, 2013 Sri Lanka it was ranked 73 out of 187 countries. But, it is disheartening to note that, still the statics by Department of Census and Statistics reveals that 313,600 families belongs to the poverty groups and each family may contain average number of 4 persons. The analysis of location of poverty also draws attention to several noteworthy features. The heaviest incidence of Absolute poverty is still to be found in the rural sector compared to the urban sector. It is about 9.4\% (Central Bank Annual Report, 2013). Therefore, Poverty is identified as the major problem that has drawn the attention of planners and program makers in Sri Lanka since independence in 1948. This has been a critical issue in other part of the world also. According to the Global Poverty and Inequality Report (2013), global official poverty rate has increased from 12.5 percent in 2007 to 15 percent in 2012 . Yet, it is mostly the developing countries that face with serious and worsening aspects of poverty. Therefore, one of the main issues in development debates is how to tackle poverty. To answer this, efforts have been made by many countries especially, through the safety net programs. There are instances in which the safety net has responded reasonably well to the challenges of the poverty. It has delivered substantial poverty relief during the great recession and this has also been modified in various ways to effectively respond to the particular demands of the poor (Global Poverty and Inequality Report, 2013). Those have resulted in increased employment and income in rural areas.

According to the Central Bank Annual Report (2013), Sri Lanka's economy recorded a rapid growth with the end of the war. It is accounted for $7.4 \%$ of the annual increase of the GDP. It has given the people a sense of hope about the future. Huge infrastructure developments were seen in almost all parts of the country. However all these developments hide the harsh reality that people in Sri Lanka are still suffering from poverty. According to the Annual Report of Central Bank (2013) Sri Lanka has recorded 8.9 percent poverty rate which is higher than that of GDP. Therefore, one of the central objectives of the development strategy of the previous government of Sri Lanka was to restore economic growth and thereby, effectively eliminate poverty from Sri Lanka. Over the years, Sri Lanka has initiated a number of anti-poverty programs; Janasaviya, School midday meal program and Samurdhi program etc. Even though many programs were implemented to solve this poverty issue, even a single does not achieved its targets (Samaraweera, 2010). Hence, many people not have seen poverty alleviation programs as serious efforts to reduce the poverty level. Programs are less consistent with other development ventures and are not fully integrated into the overall development planning process. Planners and program makers tend to be quite skeptical of the 
overall outcome of the numerous interventions of poverty projects (Kurian, 1989). Therefore, main issue that should be considered is that, whether it would be possible to derive more generalized program and operational guidelines from projects under implementation.

Though Sri Lanka has selected social development as a strategy, with preference to growth in the redistribution of wealth and alleviating poverty of the masses, little emphasis has made on strong growth oriented strategies to alleviate poverty (Rathnayake, 2009). He further explains that the programs designed to alleviate poverty have failed either to reduce the incidence of poverty appreciably or to make qualitative changes in the economy. Therefore, what it reflects, though many resources have been invested in these programs, the results have not been commensurate with the investments. Many efforts took to combat with poverty have ended without good results. Many problems have encountered due to and with program failures. The main roots of failures are poor targeting, implementation issues, mismanagement of resources etc. (Samaraweera, 2010).

Among the issues in program failures, major challenges remain in the implementation of the programs. In the past, many sound initiatives failed at the implementation stage of the programs (Marasinghe, 1993). There was little evidence on implementation success. Implementation process of Gamidiriya program at village level is comparatively success when the social and economic impact of project is concerned. (Samaraweera, 2010). He further explains that it also remains something to further clarify, where it hides the idea that it did not succeed at all. Also, not all the programs were successful at the implementation stage. According to the National Strategy for Poverty Reduction, (2006) they made the following observations with regards to the implementation of program targeting the poor.

'It is perhaps no exaggeration to say that implementation problems have proved to be the bane of program and program initiatives on poverty reduction. Indeed, implementation failures have become so generic that improving on implementation is now more correctly seen as a core strategic challenge rather than a mere matter of administration.'

Stripped of all technicalities, implementation problem in most developing nations is the problem of a widening gap between intentions and results (Makinde, 2005). According to the Honadle, (1979), who equates program with a building plan explains that,

'Implementation is the nemesis of designers, it conjures up images of plans gone awry and of social carpenters and masons who fail to build to specifications and thereby distort the beautiful blue prints for progress which were handed to them. It provokes memories of "good" ideas that did not work places the blame on the second member of the program and administration team...'

The above quotation shows the importance attached to program implementation and those responsible for implementing these policies. It also shows that no matter how beautiful the blueprint of a program is, a defective implementation will make nonsense of the whole program.

Further, as stated by Egonmwan, (1991), implementation in developing countries often turns out to be the graveyard of program where, the intentions of the designer of policies are often 
undermined by a constellation of powerful forces of politics and administration in cooperation with people. Little attention is paid to the subject of program implementation by program decision makers while it is often taken for granted that once a program is adopted by government it must be implemented and the desired goals achieved.

In handling the poverty problem, "Divi Neguma", poverty eradication strategy was adapted by the previous government at the beginning of 2011. This is a broad strategy focusing all the sectors including agricultural, industrial and fisheries. Through the Divi Neguma program, government has planned to ensure sustainable income and employment especially to rural families through strengthening the home- based economy which ultimately leads to eradication of poverty. The village community still represents the Sri Lankan culture and a large segment of it lives in rural areas. The rural economy plays a major role in strengthening the national economy. However, this current poverty alleviation program 'Divi Neguma' has also been highly criticized by Ratwatte, (2013) in his article titled 'Successful Previous Models Are Available; Why Divineguma?' referring to the replacement of the prior program 'Samurdhi' and as maintenance of white elephant. Silva, (2012) also stated that,

"Funds are to be collected by the so-called Divineguma Societies purportedly for village development, but in reality they will be used for political objectives and this is an attempt to consolidate power in the hands of Minister Rajapaksha". (Cited by Kurukulasuriya, 2012)

Further according to the Centre for Poverty Analysis (2013),

"The implementation structure of Divineguma is hierarchical with considerable duplication and overlap of functions, which is likely to be administratively expensive and take a large chunk of the program budget which would otherwise be of benefit to poor people. Also there does not seem to be a process for monitoring and evaluation of the program as a whole, so there is no mechanism to flag operational issues, or the effectiveness of the program as a whole. This is likely to affect the overall impact and success of the program as a poverty alleviation strategy".

The above lapse has often resulted in poor program implementation, which in effect gives rise to implementation gap. There is a program failure when, there is a sizable gap between a program decision and its implementation. Such a gap is characterized by the rich getting richer and the poor getting poorer in spite of stated program goal to the contrary (Egonmwan, 1991 cited by Makinde, 2005).

Therefore, in recent years, the program implementation has attracted much attention in the literature. However, all of them have emphasized in identifying problems of program implementation rather than looking at the success factors. Therefore, this research has undertaken drawing the attention to identify the factors towards successful implementation of the program. The research itself has program implication significance and economic significance. In terms of program significance, this study enables the government to redesign and undertake appropriate program design and implementation strategies upon measures that could bring effective implementation. In terms of economic significance, this study enables the proper management of resources where, the proper implementation will utilize the 
resources in a manner with no waste. It will also facilitate to minimize the misuse of resources in a way that the resources flow to that right program. At the same time this study will facilitate the program formulators especially for politicians in retaining the public trust on them because, the possibility to re-elect will mainly depend on the extent to which the general public will be benefited. Therefore, this research has a political significance too. Finally, the program reaches its succession means that the level of poverty reduced. So deprivations will no longer exist.

Furthermore, this research has been conducted in order to increase the awareness and interest of government and, other development partners regarding the better implementation of future programs. At this point, it will be worthwhile to highlight some of the factors which cause to implementation success, but this is not well understood by both the program makers and the public. These issues have paved the path for this investigation. Having identified the significance of the study, this will undertake in order to attain the following objectives.

\section{Objective of the Study}

This study is carrying out to find out the factors affecting on the successful implementation of the poverty alleviation policy in Sri Lanka.

\section{Research Methods}

The aim of this section is to identify the appropriate methodology for the research. Fellows, \& Liu, (2009) with various approaches of inquiry argue that, methodology choice is affected by the consideration of the scope and the depth of the problem. The objective of this research is to identify the factors towards the successful implementation. Therefore, quantitative approach could be used here.

The population for the study comprises the implementing officials, directly involved in implementing the Divi Neguma Poverty alleviation program at three levels of the government. The unit of analysis of this study was implementing officers of the Divi Neguma current program. Sample of 131 implementing officials were selected as $1 / 3$ of the population carrying out the research representing national, district, and divisional levels. The process of selecting the right individuals for study is known as sampling. Therefore for the selection of right individuals for this research, both the probability sampling technique and the non probability technique were used. Under the probability sampling technique, the stratified random sampling was used as the main technique of developing groups from the population to derive at a sample that contain homogenous characteristics. Based on that, first implementing officers were grouped according to the level that they are serving. Then the sample was selected proportionately and used purposive sampling method for the convenience in getting the response from the study respondents.

This study uses both primary and secondary data. As the main aim of this was to identify the factors that affect on the successful implementation, survey method was applied in the way of a questionnaire where it allows gathering large number of data and large number of variables to be analyzed quantitatively. The questionnaires were hand- delivered to the respondents, sent through an electronic mail and also by post. 
Data obtained from the government sources including the Ministry of Economic Development, and the Central Bank were the main secondary sources utilized in this research. The data collected was analyzed using the Statistical Package for Social Sciences (SPSS) version 16. Descriptive statistics were used to describe the data. Descriptive statistical information typically includes measures of central tendency, dispersion, and associations between variables. Tolerance and variance inflation factor were utilized to measure the impact of multicollinearity among the variables in a regression model. Cronbach's coefficient alpha is used as measure of reliability. Several hypotheses were tested using linear regression.

\section{Findings of the Study}

The specific research question of this study is; what are the factors affecting successful implementation of poverty alleviation policy in Sri Lanka. To answering the research question the study developed its main research objective as to identify the factors which affect successful implementation of the poverty alleviation policy in Sri Lanka. Based on the research objectives it developed seven hypotheses and tested the developed hypotheses in order to ensure whether the study achieves its main research objective or not.

\subsection{The Effect of the Communication Factor on Successful Implementation}

The first hypothesis involves the effect of communication factor on successful implementation, H1: the communication is related with the successful implementation. This hypothesis was tested by using p-value of regression analysis output.

Table 1. The effect of the communication factor on successful implementation

\begin{tabular}{l|l|l|l}
\hline Variable & Beta coefficient & t-value & P-value (Sig.) \\
\hline Communication & -.037 & -.555 & .581 \\
\hline
\end{tabular}

a. Dependent Variable. Successful Implementation

The result shows that $\mathrm{P}$ value is greater than 0.05 , which is .581 . Beta coefficient reveals that communication can make an approximately three percent negative impact on successful implementation. Then there is no significant impact of communication towards the successful implementation. Hypothesis 1 was rejected.

\subsection{The Effect of the Top Management Support on Successful Implementation}

The second hypothesis involves the effect of top management support on successful implementation, H2: top management support is related with the successful implementation. This hypothesis was tested by using p-value of regression analysis output.

Table 2. The effect of the top management support on successful implementation

\begin{tabular}{l|l|l|l}
\hline Variable & Beta coefficient & t-value & P-value (Sig.) \\
\hline Top management support & -.155 & -1.311 & .194 \\
\hline
\end{tabular}

a. Dependent Variable. Successful Implementation

The results shows that $\mathrm{P}$ value is greater than 0.05 . Beta coefficient reveals that top management support can make an approximately fifteen percent negative impact on 
successful implementation. Then there is no significant impact of top management support towards the successful implementation. Hypothesis 2 was rejected.

\subsection{The Effect of the Disposition Factor on Successful Implementation}

The third hypothesis involves the effect of disposition factor on successful implementation, H3: the disposition is related with the successful implementation. This hypothesis was tested by using $\mathrm{p}$-value of regression analysis output.

Table 3. The effect of the disposition factor on successful implementation

\begin{tabular}{l|l|l|l}
\hline Variable & Beta coefficient & t-value & P-value (Sig.) \\
\hline Disposition & 0.478 & 4.795 & .000 \\
\hline
\end{tabular}

a. Dependent Variable. Successful Implementation

The results show that $P$ value is less than 0.05 . Beta coefficient reveals that disposition can make an approximately fourty eight percent impact on successful implementation. Then there is significant impact of disposition towards the successful implementation. Hypothesis 3 was accepted.

\subsection{The Effect of the Capability Factor on Successful Implementation}

The fourth hypothesis involves the effect of capability factor on successful implementation, H4: the capability is related with the successful implementation. This hypothesis was tested by using $\mathrm{p}$-value of regression analysis output.

Table 4. The effect of the capability factor on successful implementation

\begin{tabular}{l|l|l|l}
\hline Variable & Beta coefficient & t-value & P-value (Sig.) \\
\hline Capability & 0.359 & 3.682 & .000 \\
\hline
\end{tabular}

a. Dependent Variable. Successful Implementation

The result shows that $\mathrm{P}$ value is less than 0.05 . Beta coefficient reveals that capability can make an approximately thirty six percent impact on successful implementation. Then there is significant impact of capability towards the successful implementation. Hypothesis 4 was accepted.

\subsection{The Effect of the Availability of Resources on Successful Implementation}

The fifth hypothesis involves the effect of availability of resources on successful implementation, H5: the availability of resources is related with the successful implementation. This hypothesis was tested by using $\mathrm{p}$-value of regression analysis output.

Table 5. The effect of the availability of resources on successful implementation

\begin{tabular}{l|l|l|l}
\hline Variable & Beta coefficient & t-value & P-value (Sig.) \\
\hline Availability of resources & 0.150 & 1.845 & .070 \\
\hline
\end{tabular}

a. Dependent Variable. Successful Implementation

The results shows that $\mathrm{P}$ value is greater than 0.05 . Beta coefficient reveals that though 
availability of resources can make positive impact on successful implementation there is no significant impact of availability of resources towards the successful implementation. Hypothesis 5 was rejected.

\subsection{The Effect of the Number of People Involved on Successful Implementation}

The sixth hypothesis involves the effect of number of people involved on successful implementation, H6: the number of people involved in implementation process is related with the successful implementation. This hypothesis was tested by using p-value of regression analysis output.

Table 6. The effect of the number of people involved in implementation on successful implementation

\begin{tabular}{l|l|l|l}
\hline Variable & Beta coefficient & t-value & P-value (Sig.) \\
\hline $\begin{array}{l}\text { Number of people involved } \\
\text { in implementation }\end{array}$ & -.162 & -2.298 & .025 \\
\hline
\end{tabular}

a. Dependent Variable. Successful Implementation

The results show that $\mathrm{P}$ value is less than 0.05 . Beta coefficient reveals that number of people involved in implementation can make an approximately sixteen percent impact on successful implementation. But it is negative relationship. Then there is significant impact of number of people involved in implementation towards the successful implementation. Hypothesis 6 was accepted.

\subsection{The Effect of the Past Experience on Successful Implementation}

The seventh hypothesis involves the effect of past experience on successful implementation, H7: the past experience is related with the successful implementation. This hypothesis was tested by using $\mathrm{p}$-value of regression analysis output.

Table 7. The effect of the past experience on successful implementation

\begin{tabular}{l|l|l|l}
\hline Variable & Beta coefficient & t-value & P-value (Sig.) \\
\hline Past experience & 0.404 & 4.467 & .000 \\
\hline
\end{tabular}

a. Dependent Variable. Successful Implementation

The results show that $\mathrm{P}$ value is less than 0.05 . Beta coefficient reveals that past experience can make an approximately fourty percent impact on successful implementation. Then there is significant impact of past experience towards the successful implementation. Hypothesis 7 was accepted.

Initially this study developed seven hypotheses. But, all the hypotheses defined in the study were not accepted. In other word, factors such as communication, top management support, and availability of resources tested in the model have no statistically significant impact on successful implementation of poverty alleviation policy in Sri Lanka. However, capability, number of people involved, disposition, and past experience have a statistically significant impact on successful implementation of poverty alleviation policy in Sri Lanka. Therefore, following table will summarize the results of hypotheses testing. Accordingly, proposed 
model also can be illustrated.

Table 8. Summary of the Hypotheses Testing

\begin{tabular}{ll}
\hline Hypotheses & Rejected/Supported \\
\hline H1 & Rejected \\
H2 & Rejected \\
H3 & Supported \\
H4 & Supported \\
H5 & Rejected \\
H6 & Supported \\
H7 & Supported \\
\hline
\end{tabular}

Based on the findings derived at the statistical test it enables to develop a new model as depicted below.

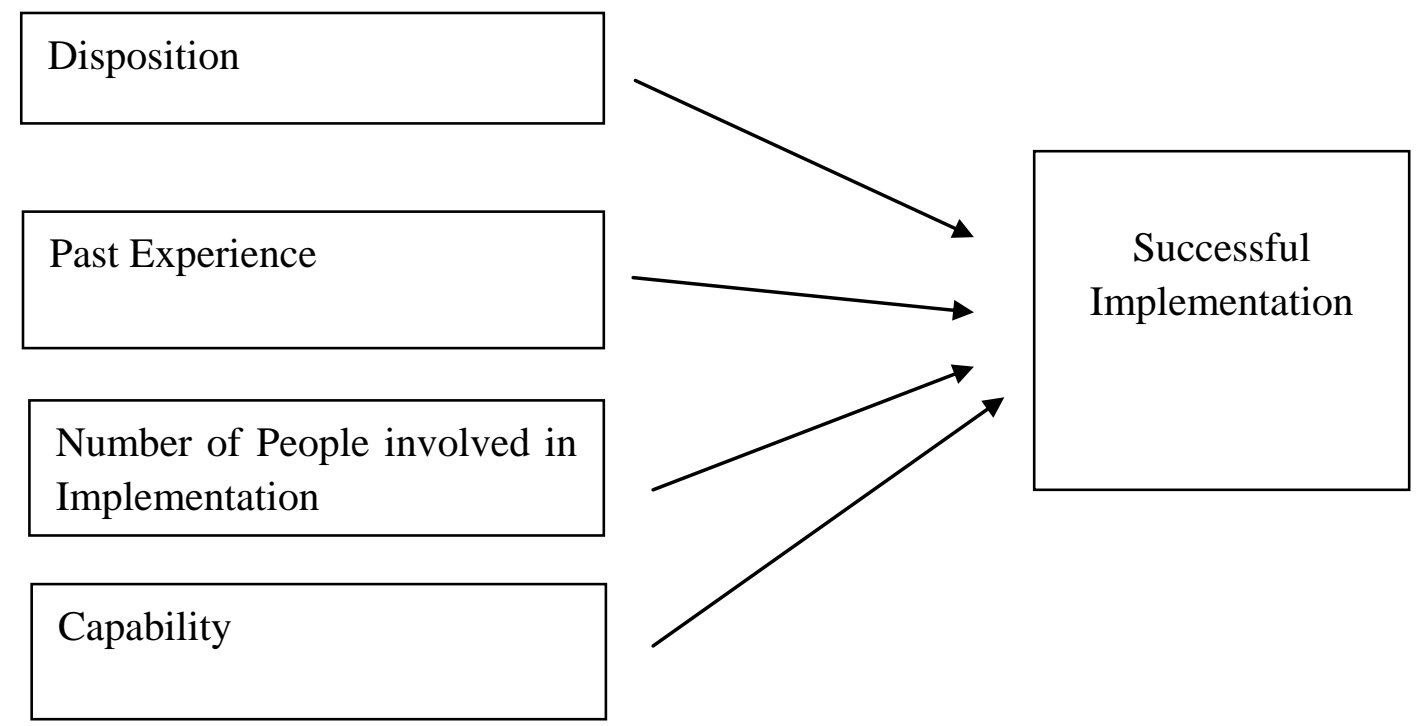

Figure 1. Proposed Model of the Study

Source: Compiled by the author based on data analysis

According to the findings, determinants of successful implementation of poverty alleviation policy are disposition factor, past experience of implementing officers, number of people involved in the implementation, and capability factor.

\section{Discussion}

The study on successful implementation constitutes a wide range of conceptual and empirical works. However, it is very rare to find out the similar studies related with the poverty alleviation programs. Though, it could be found out some research studies on identifying the factors which brings implementation success, those were based on the qualitative techniques as the source of collecting data, mainly it was the interviews. In analyzing also prior studies used the qualitative techniques. No statistical methods are to be seen in those research works. With these limitations, researcher integrated many factors identified by reviewing the prior research and from this study tried to measure the statistical significance of those factors. In 
other words it aims to measure how significant those factors in achieving the implementation success, especially in poverty alleviation programs in Sri Lankan context.

Thus, this study integrates communication, top management support, disposition, capability, availability of resources, number of people involved in the implementation, and past experience in order to propose suitable model to identify the factors influencing successful implementation of poverty alleviation program in Sri Lanka. The unit of analysis of this study was the implementing officers. This study found that disposition factor has the most significant impact on successful implementation, followed by past experience, capability, and number of people involved in the implementation.

A review of literature by Hailu \& Rahman, 2012, reveals that among the factors necessary for program implementation success effective communication among stakeholders often ranks high. He further explains that communicating and sharing information and knowledge about the project empowers project members to contribute for a better outcome. With support to the argument Meter \& Horn, 1979, Nah \& Lau,(2001) also stated that successful implementation requires clear program objectives, as well as accurate and consistent communication of those objectives.

But the current study results show that communication is not statistically significant as a determinant of successful implementation. Confirming the findings of the present study Zohir, (2009) revealed that the critical element that makes the program success is the disclosure of full information on eligibility and entitlements, which is not always the case in targeting the poor. The present study, determinants of successful implementation of poverty alleviation program focused on identifying the factors which determine the success in implementation of program focusing the poor or programs which targeted the poor. So the findings which is, the communication is not has a significant impact on the implementation success is compatible with some research findings. To further confirm the findings of the current study, the statistical results are commensurate with the qualitative findings of this study. Researcher was utilized both quantitative and qualitative approaches. So it was revealed that current program it is lacking the communication. So the current study indicated that revealing all the information among the people not encourage the success of the program.

Although extant literature emphasizes the influence of top management as determinant of successful implementation, (Hailu \& Rahman, 2012, Fernandez \& Rainey, 2006, Abdullah, 2012, 2008, and Collahan \& Holzer, 1998) the results of the present study found that there is no significant impact on the implementation. Hailu \& Rahman, (2012), further explain that active envelopment and support of senior management is essential to provide the necessary fuel to successfully complete the implementation of the program. Abdullah, (2012), has highlighted on how the top management can support to successfully implement the program. According to him it can be done by leveraging close personal ties and pursuing informal avenues of influence. Thus, this would be a good strategy in achieving a successful implementation of poverty alleviation programs in Sri Lanka. According to the Fernadaz \& Rainey's (2012) point of view top management is the champion which cause for successful implementation. Also champions are well committed and taking risks. So he propose that top 
management support is important and those should be well committed to achieving the success. The strategy we can apply in to the study context is, having the committed and personal risk takers in poverty alleviation programs in Sri Lanka.

The study on 'The determinants of success in implementing an expert system in state government', Meter. \& Horn (1979), reveal that implementation may fail if implementers refuse to do what they are supposed to do. He further explains how it happened. Dispositional conflicts occur because subordinates reject the goals of their superiors for numerous reasons. They offend implementers' personal values (Meter. \& Horn (1979). Thus, what it elaborates is attitudes play an important role in making success the implementation. The current study also found that disposition is significantly affect on the successful implementation. It is the factor which made the highest impact among other constructs. Of course, as pointed out previously, having favorable attitudes on the program make the implementation more success and vice versa. In strengthening the findings of the current study, Lucas (1978) and Sudharshan(2001) concluded that user attitudes are significant correlates of success of implementation. Micheal et al (2002) proposed how to deviate from the dispositional conflicts. According to him people involve in implementation should be given the responsibility in decision making. This is what we can apply in our own context. In Sri Lanka it is no exaggeration to say that people having the power may not have responsibility, and people who having the responsibility may not have the power. This is the point where it arises the dispositional conflicts. Thus, we can apply the strategy proposed by Micheal et al (2002).

Results also provide support for predictions regarding the capability factor. The hypotheses we derived was capability factor relates with the successful implementation. Thus it shows that there is a significant impact towards the successful implementation. In fact, education background of implementing officers will help them to carry out the program well, hence it will lead to success the implementation.

According to Bhatt (2004), highly educate staff are likely to be able to implement more successfully the program (Cited by Sudharshan, 2001). Capability involves both education and training. However, Bhatt (2004) further explains that strong educational background is no substitute for good training with the means of implementation. Therefore, education level of the implementing officers plays an important role here. In present study, respondents were above the qualification of degree. But, some were lack in training in particular type of program. But, study results were revealed capability is having a significant impact on successful implementation. This finding is strongly supported by Bhatt (2004). Findings by Sudharshan, (2001), Brown, (2009), and Hailu \& Rahman (2012), are also compatible with the findings of the current study.

According to Brown (2009), he added capacity factor in explaining the capability factor, by highlighting the inadequacy of the local level staff and high level of turnover of administrators at all levels to implement the program successfully. However, the current study does not taken the capacity under capability factor, since the researcher put it under number of implementing actors in measuring the adequacy of number of people in the process of implementation. 
Micheal, et.al. (2002), in his research titled 'Enterprise Resource Planning: Implementation Procedure and Critical Factors' emphasize the importance of training. Further, he stressed that training should be start early preferably well before the implementation begins. So this gives us the insight that it is worthwhile in giving people the training prior to implement the program. Thus, as one of the strategy training will be regarded in the implementation literature. What most important is train people before put them into action.

The hypothesis pertaining to availability of resources not received the significance in statistical test. In contrast to the findings of the present study Burkey (2002), revealed that success is not cheap or without trade-offs. Further explains that program success involves a redeployment or redistribution of scares organizational resources toward a host of new activities and programs. Similar argument has made by Brown (2009). He emphasized that financial resources are the key. Then it will fuel right combination of other inputs. Further, Contrary to our hypothesis, availability of resources not related to successful implementation. Although surprising, there seems to be very few strong explanation for our findings. Brown (2009) stressed that resources must be both consistently available and they must be appropriately targeted. Merely throwing money at a program is not enough to guarantee its success, what matters for implementation is resources for the implementation task themselves, not simply size of budget or extent of subsidy to clients.

Further strengthening the findings of the current study, Raymond (2006) pointed out that consistent availability of sufficient resources is central to a program's ease of implementation. Thus, what it reflects in findings of Raymond (2006) there is no relationship between successful implementation and the availability of resources, while it has relationship between availability of resources and ease of implementation. Therefore, this finding may provide some avenues for further inquiry to understand spurious relationships with successful implementation.

Another hypotheses the researcher developed based on the in-depth review of literature, is number of implementing actors in the implementation process relates with successful implementation. We found that a significant impact can be made by this factor toward the success of implementation. Further, it is statistically proved that there is a negative relationship with these two constructs. For simplify the finding, less number of people will make the implementation success while, large number of people will hinder the successful implementation. Therefore, increasing the number of people in implementation process will not result in the success. Previous research done by Raymond (2006) also asserted that more the actors involved in the implementing a program greater the chance that implementation will be retarded or less successful. This is what we can see in Sri Lanka also. People are very much interest in getting the government job due to the various reasons. One of the best example we can discuss is recent past government has recruited large number of graduates as development officers to the public service. Though they have occupied under the divineguma program we couldn't experience any achievement under that program. So increasing the number of heads does not mean that it is a source of success. Thus, this indicates the implication to program makers while designing the future programs. 
Previous experience with implementing similar type of programs may have a significant impact on the program implementation. Based on that, the present study found that there is a significant relationship between successful implementation and past experience. Our findings also supported by previous studies; Raymonad (2006) and Micheal, et.al (2002). Past accomplishments will enable to do the things successfully. Raymond,(2006) stated that less experience the implementers had with similar activities previously the harder it will to be achieve success. Micheal, et.al (2002) highlighted that what type of people should be occupy in the programs in achieving the success in implementation. According to him, implementation team should be composed of top-notch people who are chosen for their skills, past accomplishments, reputation, and flexibility. This will also provide some guidelines to recruit the correct personnel to correct jobs.

\section{Conclusion}

Sri Lanka aspires to become a poverty free middle income country by 2016 . According to the Human Development Index, Sri Lanka has ranked 73 out of 187 countries. With that achievement we cannot say that we are developed nation. Further, data by department of census and statistics shows that in 2014 there are 4.9 million people in the poverty group. So, one of the main objectives of governments in Sri Lanka is making Sri Lanka a poverty free country. In reaching that broad objective it has implemented many initiatives; Janasaviya, Samurdhi, and Divineguma the well known to all. Except the truth that total eradication of poverty is impossible, it is worth to assess whether the initiatives achieved the targets or not. In assessing the previous many studies were found that many initiatives has failed at the implementation stage. Therefore, this study intended to identify the factors that would bring the implementation success.

In achieving the established objective it was utilized both primary and secondary data. Primary data were obtained through the questionnaires and unstructured interviews also conducted. Implementing officers at national, district, and divisional level were the respondent of the study. The study used SPSS version 16.0 in analyzing the data to identify the significant of each factor towards the successful implementation.

By carrying out thorough investigation on the topic factors affecting on successful implementation of poverty alleviation policy in Sri Lanka, this study found that disposition, capability, past experience, and number of people involved are the key determinants of successful implementation. Supported by the previous studies this study found that disposition is the main determinant of successful implementation, followed by past experience, capability, and number of people involved. All factors, except number of people involved have a positive relationship. Number of people involved in the implementation process has a negative relationship with the successful implementation.

In sum all are not perfect. People can learn from past mistakes. Nothing we can do with the past. Things have to be done with future. Thus, this study would be the eye opener of leaders of government who put the poverty eradication as priority. It is hoped that future designers and implementers of poverty alleviation initiatives of Sri Lanka will positively act in this regard. Hence, following suggestions can be drawn. 
- Make favorable attitudes among the implementing officers about the program. In doing so, always give them the responsibility, and then, it will create 'WE' attitude among officers.

- Always keep close ties with the implementing officers.

- Utilize the people who have prior experience on the similar programs.

- Make recruitments to the programs based on the education level of the people.

- Less is better. So avoid the mass scale recruitments.

- Proper targeting mechanism should be established.

Further, it is believed that future researchers may reflect positively on this work, despite its apparent limitations. Further development offered here will help to make advance understanding in the important area of successful implementation and how it is achieved in poverty alleviation policy.

\section{References}

Abdullah, A. (2012). Workforce Localization Policies in Saudi Arabia; The determinants of successful implementation in multinational enterprises. In: Management knowledge and Learning International Conference, London 2012, 39-42. https://doi.org/10.2307/20045917

Burkey, S. (2002). People first: a guide to self-reliant participatory rural development. Zed Books Ltd. Retrieved August 12, 2013 from: http://www.cabdirect.org/abstracts/19931803346.html;jsessionid=914E45699641664744CE3 A3C02791E18

Central Bank of Sri Lanka. (2013). Annual Report, Colombo, Sri Lanka.

Centre for Poverty Analysis. (2013). A closer look at Sri Lanka's Poverty Figures: are we reading them right? Retrieved September 15, 2013 from: http://scholar.google.com/scholar?q=center+for+poverty+analysis\&btnG=\&hl=en\&as_sdt=0 $\% 2$ C5\&as_ylo

Egonmwan, J. A. (1991). Public program analysis: concepts and applications. SMO Aka and Brothers Press. Retrieved August 09, 2014 from: http://scholar.google.com/scholar?q=Egonmwan\%2C+J.+A.+\&btnG=\&hl=en\&as_sdt=2005 \&sciodt $=0 \% 2 \mathrm{C} 5 \&$ cites $=14724139130350574364 \&$ scipsc

Elisabath, J. U., Ronald, R. H., \& Michael, U. (2002) Enterprise Resource Planning: Implementation Procedure and Critical Factors, Europena journal of operational research. Retrieved December 02, 2013 from:www.elsevier.com/locate/ds

Fellows, R. F., \& Liu, A. M. (2009). Research methods for construction. John Wiley \& Sons Retrieved December 23, 2013 from: http://scholar.google.com/scholar?q=fellows $+\% 26+$ liu\&btnG=\&hl=en\&as_sdt=0\%2C5

Fernandez, S., \& Rainey, H. G. (2006). Managing successful organizational change in the Public Sector. Public Administration Review. https://doi.org/10.1111/j.1540-6210.2006.00570.x 
Global Poverty and Inequality Report. (2013) The Stanford center on Poverty and Inequality. Retrieved December 12 , 2013 fromhttp://web.stanford.edu/group/scspi/sotu/SOTU_2014_CPI.pdf

Hailu, A., \& Rahman, S. (2012). Evaluation of Key Success Factors Influencing ERP Implementation Success. In Services (SERVICES), 2012 IEEE Eighth World Congress on 88-91. https://doi.org/10.1109/SERVICES.2012.74

Honadle, G. (1979). Implementation Analysis: The Case for an Early Dose of Realism in Development Administration. International Development Administration, New York: Praeger. Retrieved August $\quad 09, \quad 2013$ from: http://scholar.google.com/scholar?cites=14724139130350574364\&as_sdt=2005\&sciodt=0,5 $\&$ hl $=$ en

Kurian, N. (1989). Anti-Poverty Program: A Reappraisal. Economic and Political Weekly, 24(12), 12-20. Retrieved December 19, 2014, from http://www.jstor.org/stable/4394564

Kurukulasuriya, L. (2012). Divineguma facilitates the concentration of power. The Sunday Times. Retrieved September 30, 2012 from: http://www.sundaytimes.lk/120930/columns/divineguma-facilitates-the-concentration-of-pow er-14510.html

Lucas, H. C. (1978). Empirical Evidence for a Descriptive Model of Implementation. MIS Quarterly, 2(2), 27-42. Management Information Systems Research centre. https://doi.org/10.2307/248939

Makinde, T. (2005). Problems of program implementation in developing nations: the Nigerian experience. Journal of Social sciences, $11(1), \quad 63-69$. https://doi.org/10.1080/09718923.2005.11892495

Marasinghe, M. L. (1993). Poverty Elimination through Poverty Alleviation: The Jansaviya Programme of Sri Lanka for National Development, Third World Legal Studies, 12(24). Retrieved December 19, 2014 from: http://scholar.valpo.edu/twls/vol12/iss1/2

Meter, V., \& Horn, V. (1979). The determinants of success in implementing an expert system in state government, Public Administration review, 58(04), Retrieved February 12, 2013 from: http//scholar.google.com/vol58/4

Nah, F. F. H., \& Lau, J. L. S. (2001). Critical factors for Successful Implementation of Enterprise Systems. Business Process Management Journal, 7(3), 285-296, MCB University Press. Retrieved February 23, 2013 from: http:/www.emerald-library.com/ft

Rathnayake, R. (2009). Poverty in Sri Lanka: Incidence and Poverty reduction Strategies.

Ratwatte, C. (2013). Successful Previous Models Are Available; Why Divineguma? Daily FT. Retrieved December 21, 2013 from: http://www.ft.lk/category/columns/charitha-ratwatte/page

Samaraweera, G. (2010). Economic and social assessment of poverty alleviation programs in Sri Lanka-special reference to the Gemidiriya community development and livelihood 
improvement project. Journal of Emerging Trends in Economics and Management Sciences, 1(1), 60-65. Retrieved August 12, 2013, from http://reference.sabinet.co.za/sa_epublication_article/s1_jetems_v1_n1_a8

Sudharshan, K. (2001). Determinants of innovation in organizations, The American Political Science Review, 63,111-126 Retrieved February 15, 2013 from: http://onlinelibrary.wiley.com/doi/10.1111/j.1541-0072.1980.tb01266.x/pdf

Zohir, S. (2009). Implementation of policies for reducing chronic poverty. Retrieved February 20, 2013 from: www.chronicpoverty.org

\section{Copyright Disclaimer}

Copyright for this article is retained by the author(s), with first publication rights granted to the journal.

This is an open-access article distributed under the terms and conditions of the Creative Commons Attribution license (http://creativecommons.org/licenses/by/4.0/). 